\title{
OBSERVATIONS ON THE SURGERY OF THE SPLEEN.
}

\author{
By SIR JOHN BLAND-SUTTON, LONDON.
}

MY interest in the spleen began early: I remember as a boy watching a taxidermist skin a bird; during the evisceration he showed me the bird's milt, or spleen, and remarked dryly, Physiologists do not know the functions of the spleen, but dogs and men can live without it. My interest was quickened on learning that the pain, or stitch, in the inside, so annoying to those who run, is caused by the spleen swinging on its suspensory ligament.

It is believed by many, though I have failed to find a definite statement on the matter, that the Romans removed the spleen of some of the gladiators in order that they might perform feats of endurance with greater ease.

Pliny (A.D. 23-79) makes the following observation in regard to the spleen : "Sometimes it is a peculiar hindrance to runners, so that they burn it away from those runners who are incommoded by it. Animals, it is said, have had it removed and yet lived."

Although these statements do not contain anything explicit, they indicate the existence of a tradition even before the Christian era, that men and animals could live without a spleen.

Adelmann, in an admirable survey of the records of splenectomy to 1887 in reference to total extirpation of the spleen, mentions a case in which the spleen being prolapsed through a wound involving the false ribs, Viard ( $\mathrm{I}_{58 \mathrm{r}}$ ) tied the vessels and removed the spleen; the patient recovered. In I84I. Bardeleben extirpated the spleen and the thyroid gland from a dog; the animal recovered and lived in good health six years. It died from the impaction of a cystin calculus in the urethra. Thus, in I 865 , when I received my first informal lesson in physiology, there was justification for the taxidermist's opinion that dogs and men could live without the spleen.

Splenectomy was not a recognized surgical operation until the latter half of the nineteenth century. In the interval between I860 and 1890 , ovariotomy began to be performed with some measure of success; this prompted surgeons to undertake the removal of enlarged spleens; but the appalling immediate results of indiscriminate splenectomy, especially when the spleen was removed for leukæmia, threatened to exclude excision of the spleen from the sphere of legitimate surgery; the admirable results which followed the judicious selection of cases since I89o serve, however, to show that the operative risks are not greater than those of ovariotomy.

Experience teaches that the spleen can be removed without causing any serious physiological disturbance, except in the condition known as leukæmia, where its removal is quickly followed by death from shock or hæmorrhage. Nevertheless, splenectomy should not be lightly undertaken, for it is often a severe operation.

The spleen has been removed for many pathological conditions; but since VOL. 1. - NO. 2. 
I89o surgeons have ascertained the limits of splenectomy. The following conditions justify the removal of the spleen :-

I. Injuries, such as rupture, stabs, gunshot wounds and the like, for they endanger life from hæmorrhage.

2. When enlarged and mobile the spleen is dangerous to itself, and may interfere with other viscera.

3. When the seat of malignant disease, or occupied by an echinococcus colony, or cystic from causes none can tell.

4. Splenomegaly (great spleen) associated with changes in the number, as well as in the relative proportion, of the blood corpuscles, such as exist in the conditions known as anæmia and the conglomerate group covered by the term Banti's disease.

5. Morbid conditions blood-borne, such as abscess due to the lodgment of septic emboli, tuberculosis, infarcts, and thrombosis of the splenic vein.

6. Among exceptional conditions justifying removal of the spleen may be mentioned aneurysm of the splenic artery (Winckler). In the course of removing large perirenal tumours, also in performing gastrectomy, surgeons have found it necessary to remove the spleen when it has been implicated by the growth. In such circumstances the splenectomy becomes an incident in an operation.

Noguchi removed a lipoma four feet in diameter and weighing $33 \mathrm{lb}$. from a man aged forty-two. The spleen adhered so firmly to the tumour that it was removed also. He saw the patient six years afterwards and made a microscopical examination of his blood. The man's condition was so satisfactory that Noguchi expressed the opinion that in similar circumstances the surgeons need not hesitate to remove the spleen. My experience leads me to the same conclusion.

\section{INJURIES OF THE SPLEEN.}

In the majority of instances, rupture of the spleen is a rapidly fatal accident ; death in some cases has been as speedy as when an aneurysm of the aorta has burst. The causes and consequences of injuries to the spleen vary widely. The spleen is injured by kicks from horses and from men; falls upon pointed and angular objects, rails or ridges; falls on the belly when drunk and even when sober, especially if the spleen is enlarged; crushes by moving vehicles such as carts, carriages, motor-cars, or locomotives; blows from a cricket ball or a shovel; stabs in warfare or civil broils, and bullet wounds. When the spleen is injured by the passage of a vehicle or a severe crush, it is often complicated by fracture of the overlying ribs. Malarial spleen or ague-cake is especially liable to be ruptured, even from such slight causes as straining during vomiting, coughing, or sneezing.

It is unusual for the spleen to be badly injured without some damage to adjacent organs, except it be enlarged. Among curious modes of injury the following are worth mention :-

The spleen has been ruptured in a new-born infant dropped on the ground in a precipitate labour (Coutagne). Vincent performed cœliotomy on a woman, aged 28, in Algiers, expecting to remove a large ovarian cyst, but he found a black mass. During the manipulation his hand broke it ; there was free bleeding, and the tumour was recognized as an ague-cake. The hole in the spleen was 


\section{SURGERY OF THE SPLEEN}

stuffed with gauze; a sinus persisted for a long time, and black material escaped. It eventually closed, and nearly a year later the spleen had disappeared. The woman was in good health. Varnek operated on a young woman and succeeded in removing piecemeal something which he regarded as an adherent uterine fibroid. When the tumour was examined in the laboratory it was found to be a spleen.

Gunshot Wounds.-Bullet wounds of the spleen are not common in civil practice. The normal spleen tucked under the left costal arch does not offer a big target; but bullet wounds of this organ do happen, and they are very fatal, for such a wound to a vascular body like the spleen is attended with alarming bleeding and the bullet nearly always injures adjacent organs: such injuries increase the jeopardy to life, and handicap the surgeon in his efforts to treat them. The following case under my own care illustrates these points : A footman, aged I7, shot himself in the chest with a revolver because the girl he loved did not requite his love. The bullet ('32) entered the chest in the fifth intercostal space half an inch below the left nipple. In the course of the operation (which entailed opening the thorax through a vertical incision involving the lower costal cartilages, and the abdomen in the left semilunar line) it was discovered that the bullet had traversed the lung, the stomach, and the spleen, and it was extracted from beneath the skin of the back. Ten ounces of blood were removed from the left pleural cavity; many ounces were sponged from the abdominal cavity. A hole was sutured in the anterior, and one in the posterior, wall of the stomach at its cardiac pole, and the spleen, which had been traversed by the bullet, was bleeding freely. The pedicle was transfixed with silk and the spleen removed. The boy nearly died during the operation, but rallied when transfused freely with normal saline solution. Recovery was retarded by an empyema; this required resection of a portion of a rib, and drainage. The pus contained $B$. coli. The boy recovered, and the girl, finding the youth so ready to sacrifice himself for unrequited love, softened her heart; the pair are contented with each other now, although the accident went near to swelling the list of love stories with tragic endings.

The signs of severe injury to the spleen are those incidental to internal bleeding: pallor, dilated pupils, coldness of the skin, and rapid failure of the pulse. In very exceptional instances, when a large quantity of blood escapes into the belly, it may give rise to shifting dullness on percussion. The amount of blood lost varies greatly. When a rupture of the spleen involves the splenic artery or vein, rapid death from loss of blood is the rule.

Rupture of the Spleen is not always fatal. The museum of St. Bartholomew's Hospital contains a spleen from a woman who fell from a window and broke her femur; she died ten days later. At the post-mortem examination it was seen that the spleen had been torn across, and the torn surfaces had united. There was an encapsuled collection of blood around the organ.

In order to be successful, the treatment of rupture of the spleen should be prompt. In cases where the lesion is so serious as to demand quick intervention, there is generally such damage to the organ that the only way effectively to arrest the bleeding is by removal of the spleen. As a rule, splenectomy under these conditions is a simple proceeding. Tentative measures, such as packing with gauze and drainage, have answered in some cases. We know that 
occasionally patients with a ruptured spleen have recovered by what is known as " trusting to luck," but experience teaches that splenectomy is the best mode of treating such lesions. The crudest surgery is occasionally followed by success: A Rajput, aged 35, had the left side of his belly ripped by a boar. and the spleen protruded. The surgeon who saw the man at the time of the accident could neither make out the nature of the body hanging from the wound nor replace it. Nearly a month later the wound had healed, leaving the spleen outside. It contracted, and rested sessile on the abdominal wall. In this condition it resembled a Tam o' Shanter cap. Brown, who then saw the case, tied the vessels and removed the spleen. The man recovered.

MOVABLE OR WANDERING SPLEENS.

The epithet " movable," or "wanciering," has been applied by surgeons to organs unduly mobile, the common examples being a mobile kidney and a wandering goitre: in none is the term so well deserved as in the case of a very movable spleen. In a well-marked instance, this organ is capable of such free excursions that it can be brought in contact with every part of the abdominal and pelvic cavities. It is difficult to conceive that the spleen, suspended to the under surface of the diaphragm by the phrenico-colic ligament (peritoneal), to the great cul-de-sac of the stomach by means of the gastro-splenic omentum, and connected to the pancreas by blood-vessels, could so elongate its attachments as to reach the floor of the pelvis. So many cases of wandering spleens have been described that it is possible to give an account of the mischief such spleens set up in the abdomen, the difficulty they cause in diagnosis, the disaster such spleens sometimes entail on their owners, and the astonishment which follows their discovery in the operating theatre or post-mortem room. It is a fact that wandering spleens are almost confined to women, and especially women who have had children. It is well to remember that there is no change which disturbs the abdominal viscera so much, and leaves such traces, as pregnancy.

There can be little doubt that the common cause of wandering spleen is increase of bulk. Such a spleen will occupy various positions in the abdomen. Occasionally it will hang in its normal place and remain for days under the left costal arch; then it will suddenly slip out and become obvious to the patient in the umbilical or iliac regions, or descend into the pelvis and imitate a pelvic tumour. All wandering spleens tend to drop into the pelvis, where they displace, and sometimes cause complete prolapse of, the uterus. When a patient with a very mobile spleen lies on her back, the spleen will fall to one side or the other; sometimes it floats on the intestines like a boat on the crest of a billow.

The effects produced by wandering spleens are remarkable, for the wandering leads to changes in the spleen and produces mechanical effects on the abdominal organs with which it comes in contact. The spleen is a contractile organ. Rhythmic movements of contraction take place at intervals of about a minute in cats and dogs. Under normal conditions the vascularity and distensibility of the spleen is very great, and these features are greatly enhanced when it hangs pendulous at the end of an elongated artery and vein. The engorgement of a spleen, when it revolves and twists its pedicle, is enormous. Pregnancy appears to be a cause of axial rotation of wandering spleens, and this accident leads to the same severe symptoms with which we are more familiar in the case 


\section{SURGERY OF THE SPLEEN}

of ovarian cysts. Permanent occlusion of the splenic artery and vein by axial rotation involves atrophy of the spleen.

The effects produced by a wandering spleen on the viscera are many and various. The intimate relation of the pancreas to the spleen leads to the lengthening of this gland. Sometimes the pancreas is so stretched that its tail has reached into the pelvis when involved in a twisted pedicle. On several occasions the tail of the pancreas has been included in the pedicle when it has been necessary to perform splenectomy. I have had such an experience. Urbinati (r874) reported a case in which the stomach was involved in the twisted portion of the pedicle of a wandering spleen. The intestines are sometimes entangled in this way: small intestine, colon, sigmoid flexure, or vermiform appendix. Septic peritonitis arises from such complications, due to infection from the bowel.

In my former writings on the disturbances caused by a wandering spleen, I attributed the jaundice, which is sometimes associated with it, to mechanical obstruction of the common bile-duct due to the spleen dragging on the duodenum and stomach. A better explanation is now available (see the paragraph on acholuric jaundice and splenomegaly).

A wandering spleen may give rise to the physical signs presented by many forms of abdominal tumours and uterine fibroids. Previous to 1890 a wandering spleen had rarely been diagnosed; and when enlarged and big enough to reach the pelvis it is usually regarded as an ovarian tumour. Now that enlarged and movable spleens are included in the tables of diagnostic probabilities among abdominal and pelvic tumours, any freely movable tumour with the contour of a spleen in the abdomen or the pelvis, is suspected to be a wandering spleen. Cases have been reported in which such a spleen has been mistaken for renal swellings, especially mobile kidneys and hydronephrosis.

A pelvic spleen mimics very closely the physical signs of a pedunculated subserous fibroid. For example: A woman, aged 33, noticed a lump low in her belly shortly after the birth of her youngest child. This was regarded by her medical attendant as a pedunculated subserous fibroid; it could be moved easily into the left iliac fossa and the hypogastrium. On vaginal examination the lower pole of the tumour could be felt in the recto-vaginal fossa. When the patient lay on her back and breathed deeply, the tumour appeared to be tugged out of the pelvis. As that part of it which projected into the hypogastrium was not hard like a fibroid, and a notched border could be felt, I came to the conclusion that the supposed fibroid was a pelvic spleen. I performed splenectomy, May, I906. A few days after the operation the patient complained of pain in the legs, especially the thighs, and the temperature remained for several days between $100^{\circ}$ and $102^{\circ}$. On the twelfth day a quantity of pus escaped from the rectum, and the patient rapidly recovered. She was in good health seven years later.

\section{ENLARGEMENTS OF THE SPLEEN DUE TO INFECTIONS CONVEYED BY THE BLOOD-STREAM.}

The spleen is an extremely vascular organ, and the circulation of the blood through it is slow; in many morbid conditions of the liver the spleen acts as a reservoir for the portal circulation. There is a rare phenomenon associated 


\section{THE BRITISH JOURNAL OF SURGERY}

with such engorgement, known as a pulsating spleen. The combination required for its production is aortic regurgitation or hypertrophy of the left ventricle without valvular disease, and acute splenic enlargement due to an infective fever.

The slowness of the blood-current through the spleen favours the deposition of micro-organisms which the circulating blood may contain, as well as emboli and minute parasites. Temporary enlargement of the spleen is frequently detected in acute infective diseases such as typhoid, typhus, and pyæmia. In some instances the infection ends in suppuration-abscess of the spleen.

I. Abscess of the Spleen.-A collection of pus in the spleen arises from several causes: it may be the sequel of an injury, due to infection of extravasated blood, or the lodgment of an embolus charged with streptococci; the infecting agent may be the pneumococcus, or the amoba of dysentery.

It is difficult to diagnose a splenic from a subphrenic abscess. Collections of pus coming under the clinical denomination abscess of the spleen are often localized abscesses due to suppurative peritonitis. In some of these conditions the surgeon may find it necessary to remove the spleen, and there are conditions in which the removal of this organ facilitates convalescence.

In a case of perisplenic abscess, due, I think, to perforation of the splenic flexure of the colon, in a woman aged 35, I accidentally broke the spleen in halves in the course of an operation performed for its relief. I removed the fragments of the spleen. This happened in I897. Sixteen years later the woman was in good health.

Enlargements of the spleen due to infection are more likely to come under the observation of surgeons in the chronic forms arising from malaria, tuberculosis, and syphilis.

2. Malarial Spleen.-Enlargement of the spleen is a recognized feature of chronic malaria. Such enlarged spleens are known as ague-cakes; some of them attain an enormous size and become a burden to the patient. Splenectomy for the removal of such spleens has been performed on many patients, with, on the whole, indifferent success. An analysis of the conditions indicates that when a malarial spleen is mobile (or wandering) it can be removed with a fair prospect of success. When a malarial spleen is in its normal place or occupies the pelvis, if it be adherent from perisplenitis, the risks of splenectomy are enormously increased. Johnston, in a recent report (I908) on splenectomy, collected records of II3 cases in which the spleen had been removed for "malarial hypertrophy," and mentions, on the authority of Jonnesco, that the repeated performance of splenectomy for this condition is based on the mistaken idea that the spleen continues to be a habitat for the malarial parasite.

McGraw has recorded an unusual sequel to splenectomy for an ague-cake. He removed from a woman, in June, I887, a large malarial spleen which occupied her pelvis and presented the clinical signs of an ovarian cyst. The convalescence was troublesome. In March, I888, she had hæmoptysis, and a month later, after a fit of coughing, she spat up the connected loops of sills used for the pedicle and presented them to the surgeon. A perusal of McGraw's description of this case shows that he took care to make his silk threads 


\section{SURGERY OF THE SPLEEN}

sterile; "The thread had been rendered aseptic by first boiling in a solution of bichloride of mercury (I-IOOO), and afterwards boiling in clear water."

Captain F. E. Wilson, from observations on malarial patients at Meshed, Persia, has drawn attention to the frequency with which splenic abscess occurs in patients with malarial cachexia. He points out that when a patient with malaria and splenic enlargement suffers from fever (even under thorough quinine treatment) after the disappearance of the parasites from the peripheral blood, and there is evidence of softening, pain, adhesion of the spleen to the parietes, and leucocytosis, these signs indicate the existence of a splenic abscess. He furnishes short notes of three cases. He believes that such abscesses are due to " necrosis of areas of hypertrophied splenic tissue followed by infection from the blood-stream." Wilson had no means at his disposal for detecting the infecting agents.

3.- Tuberculous Spleen.-It is true that tuberculosis of the spleen is always secondary to a primary tuberculous focus in some other organ. A perusal of the published cases in which splenectomy has been performed for this condition makes it clear that a tuberculous spleen comes as a surprise to the surgeon in the course of the operation. It certainly did in my case. The patient had a tumour diagnosed as a wandering spleen. We knew she had a quiescent tuberculous cavity in her lung, but were astonished, on exposing the spleen in the course of the operation, to find it beset with tuberculous deposits. The woman derived great benefit from the operation, and was in good health three years later. C. Marriott had an equally successful case. I have failed to find any other examples of splenectomy for tuberculous splenomegaly in England. Fischer (I 909 ) only succeeded in collecting records of twelve cases from the literature of a continent.

4. Syphilitic Spleen.-The visceral lesions of syphilis do not spare the spleen, and it is sometimes greatly enlarged by gummatous deposits. The diagnosis of such a condition is not easy, and in consequence, the spleen has been excised on several occasions for this disease.

I saw a surgeon remove from a woman, aged 33, a spleen greatly enlarged and bosselated with gummatous deposits. She recovered from the operation, but her general condition did not improve. She was re-admitted to the hospital two years later, and died. At the post-mortem examination the liver was beset with gummata.*

5. Echinococcus Disease of the Spleen.-Many examples of echinococcus cyst and colonies in the spleen have been described. Very large colonies have been mistaken for ovarian cysts. Most of our knowledge of hydatids of the spleen is derived from observations in the post-mortem room.

Hydatids occur in the spleen in two forms. The rarer is a solitary cyst. Of this there is an excellent example in the collection of pathological spleens at St. Bartholomew's Hospital, London. It is an ovoid cyst as big as an ostrichegg, lodged in the middle of the spleen; each pole of the cyst is covered with a patch of splenic tissue, and a thin stratum of splenic pulp covers the circumference of the cyst on the side opposite to the hilum. The cyst contains degenerated echinococcus vesicles and membrane. This spleen was obtained 


\section{THE BRITISH JOURNAL OF SURGERY}

post mortem from a woman, aged 54, who died of acute bronchitis in an

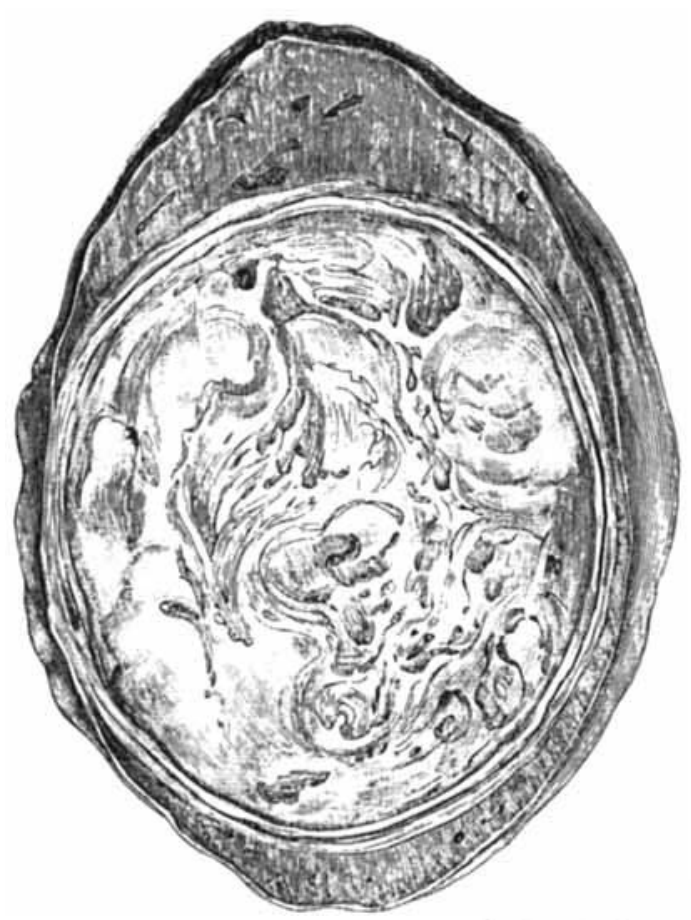
asylum. There were no symptoms during life to draw attention to the spleen. No other cysts were found in the woman. An examination of the specimen shows that the spleen with its echinococcus colony could have been easily removed (Fig. 68).

In the same collection there is a spleen with multiple hydatid cysts. There were other cysts in the patient's abdomen, especially between the liver and the diaphragm. A study of these two specimens illustrates the mode by which the spleen was invaded by these parasitic colonies. The six-hooked embryo prefers loose subserous tissue, and in the case of the spleen the parasites occupy the loose connective - tissue

Fig, 68.-Solitary Echinococcus Colony IN the SPLEen. (Museum, St. Bartholonete's Hospital.)

meshes of the gastro-splenic omentum, and gradually invade the splenic pulp from the hilum. This is well seen in the spleen which contains multiple hydatids (Fig. 69).

In the case of the solitary cyst, if the parts be critically examined, a thin stratum of the splenic pulp will be seen to cover the periphery of the cyst opposite the hilum, showing that as the echinococcus colony increased in size, it spread out and flattened the tissue of the spleen in the same way that tumours arising in the paradidymis flatten out the secreting tissue of the testis until it is like a strap.

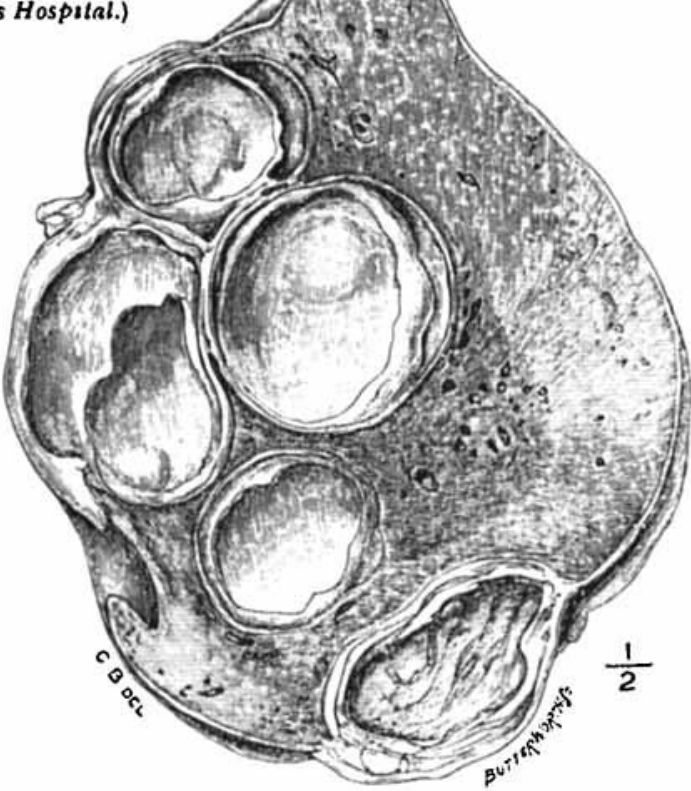

Elg. 69.-Multiple Echinococcus Cysts of the Spleen, (Muscum, St. Bartholomete's Hospital.) 
Removal of the spleen for hydatid cysts is a rare operation. The majority of the recorded cases were treated by the antique and clumsy method of incision and drainage.

\section{SPLENOMEGALY.}

This is a useful title to cover a number of splenic enlargements following a disturbance of its function excited by causes at present unknown. The discovery of the importance of the bone-marrow in blood-formation altered the physiologist's view of the function of the spleen. Red corpuscles are formed in the spleen during foetal life, but this office is transferred to the bone-marrow soon after birth. The spleen removes from the circulation broken-down red corpuscles, and the products of their disintegration are conveyed to the portal circulation to be further elaborated. This is a matter of importance. Perturbations of the hepatic functions are noticed in association with increased size of the spleen, and such disturbances are sometimes manifested by jaundice. Until recently, jaundice occurring in association with splenomegaly was attributed to mechanical interference with the outflow of bile into the duodenum; to-day we know that it is due to causes more subtle. The careful investigations which have been made into the relations between splenic disturbances and the numerical as well as the physical conditions of the corpuscular elements of the blood, have furnished a new method of clinical classification.

It is odd that an enlarged spleen may be associated with opposite conditions of blood such as erythræmia and anæmia. In erythræmia (Vaquez's disease) the blood contains too many corpuscles, and in anæmia too few. In erythræmia, instead of 5 million red and 6 thousand white corpuscles per cubic millimetre, the numbers may run up to Io or even I2 million red and 24 thousand white corpuscles, with a large increase in the proportion of hæmoglobin. The enlargement of the spleen is variable; in some of the reported cases, its lower pole has reached the iliac fossa.

The clinical features of erythræmia are plethora, cyanosis, and splenomegaly. It is, in all probability, a primary disease of the red marrow. The enlargement of the spleen in this disease is due to increased functional activity, and also in part to engorgement owing to an increase in the total volume of the blood.

Leukæmia is another remarkable blood disease associated with splenomegaly, changes in bone-marrow, and profound alterations in the number and physical condition of the corpuscular elements of the blood.

Under normal conditions, the proportion of white to red corpuscles is I-500, but in leukæmia the white may be I-5 red, or even exceed the red corpuscles in number.

These large leukæmic spleens are objects of dread to surgeons. Probably all patients who have had such spleens removed, promptly died from hæmorrhage or shock. About 1890 , the importance of a microscopic examination of the blood as a method of distinguishing the leukæmic spleen began to be recognized. To-day an abdominal tumour resembling a spleen suggests a blood-count. Leukæmia is easily recognized by the microscopic features of the blood.

In erythræmia and leukæmia surgery has no place, but a surgeon should be familiar with these conditions, for if he attempts the removal of the spleen in these diseases the enterprise can only end in disaster. 
Enlarged spleens associated with anæmia constitute an important group. This combination occurs in children and adolescents. The condition is characterized by slow, progressive enlargement of the spleen, associated with diminution in the number of the red and white corpuscles.

In I 895, I removed a big spleen from a little girl on account of anæmia and splenomegaly. The child, aged five years, is probably the youngest on which splenectomy has been performed. The girl has grown into an attractive, healthy woman, aged twenty-three (IgI3), and works as a compositor in her father's printing works. This is a good proof that the removal of the spleen in childhood does not interfere with growth and development.

There is a form of splenomegaly accompanied by anæmia (hæmolytic anæmia) and jaundice, but no bile appears in the urine (acholuric jaundice). This is a familial disease of which the leading features have been admirably summarized by F. Parkes Weber; they are: Chronic jaundice, splenomegaly, and a variable degree of anæmia. The jaundice is slight, and is not accompanied with icteric pruritus, xanthoma, or clubbing of the fingers. The fæces are nearly always well coloured, and the urine is nearly always free from bilirubin. The blood serum is abnormally yellow and contains bile pigment. There is always some anæmia (oligocythæmia), and the red cells easily hæmolyse. The spleen is nearly always enlarged and easily palpated, but it is not tender. I have removed two spleens for this disease. One of the patients, a female, aged 22, was under the care of Dr. Essex Wynter in I9I2. The splenectomy was followed by good consequences, and the jaundice disappeared; the spleen weighed $3 \mathrm{lb}$. In I895 I removed a huge spleen from a girl aged I7. She was jaundiced and anæmic. Ten years later she was in good health and actively engaged as a teacher. At the date when her spleen was removed, acholuric jaundice had not been separated as a clinical entity.

There is also a conglomerate group known as Banti's disease. The leading features of this group are: Splenomegaly associated with a reduction in the number of the blood corpuscles, red and white, and, in the later stages of the disease, with cirrhosis of the liver, occasional jaundice, and ascites.

It is difficult to distinguish Banti's disease accurately-especially when its. later stages are complicated with gastric hæmorrhages-from a group of symptoms set up by thrombosis of the portal vein. Any disease which interferes with the portal vein causes enlargement of the spleen: for example, cirrhosis of the liver, gummata, and tumours which interfere with the portal vein.

Obliterative thrombosis of the splenic vein leads to splenomegaly and hæmatemesis. When the vomiting of blood is profuse, surgeons are apt to overlook obstruction of the splenic vein as a cause. The symptoms are sometimes so striking that a differential diagnosis may be possible. The following is an example :-

A nurse, aged 26, suffered for six years from recurring attacks of profuse hæmatemesis associated with a big spleen. The bleeding was attributed to a gastric ulcer, and the amount of blood this nurse vomited in some of the attacks was so great that the red corpuscles of her blood were reduced to 662,000 per cmm. Gradually, the corpuscular elements would increase until they reached the proportion of $3,200,000$ per $\mathrm{cmm}$. This always indicated that hæmatemesis was imminent, and this invariably happened in a few days. The patient knew 


\section{SURGERY OF THE SPLEEN}

when to expect an attack, and eventually died after a profuse hæmatemesis in I895. At the post-mortem examination the spleen contained two pale infarcts, and weighed thirty-three ounces; the splenic vein was large enough to admit the index finger ; it contained pouches, and at its junction with the superior mesenteric vein, was blocked by an organized thrombus. There was no lesion in the stomach to account for the bleeding. This nurse was sent to me for splenectomy from Australia in I895. In the light furnished by the post-mortem examination, splenectomy would have been a justifiable proceeding.

It is obvious that the hæmatemesis in this and similar cases is due to engorgement of the gastric and œsophageal veins, the consequence of obstruction to the splenic vein. This would be relieved by removal of the spleen.

Splenomegaly secondary to obstruction of the portal vein has been made the subject of careful study by Edens, and especially by Pick ; the account of the condition by the latter pathologist, based on a case in which the obstruction was due to an intravenous hæmangiomatous growth, contains some useful references.

Clinical and pathological studies of these secondary forms of splenomegaly are of some importance to surgeons interested in the surgery of the spleen. The great improvement in the results of removal of the spleen during the last thirty years is leading to an extension of splenectomy, and it is in this group of splenic disease that surgery may do good, for medical measures are admitted to be impotent.

Kidd suggests that " splenectomy ought to be tried in all cases of cirrhosis of the liver with enlargement of the spleen."

If it be true that chronic engorgement of the spleen causes increased blood destruction and a toxæmia that eventually proves fatal, removal of the spleen is justified.

\section{SPLENECTOMY.}

The mode of performing this operation varies with the position of the spleen, and this concerns not only the best site for exposing the organ, but also the method of securing the pedicle.

The spleen is supplied with blood by the splenic artery, which is derived from the cœliac axis, and is of large size in proportion to the spleen. As this artery approaches the spleen it breaks up into seven or more branches ; in addition to supplying the spleen it distributes branches to the pancreas, and between the layers of the gastro-splenic omentum numerous branches-the vasa breviaramify over the great cul-de-sac of the stomach, and one larger branch, the left gastro-epiploic artery, running between the layers of the great omentum, distributes branches to the greater curvature of the stomach and inosculates with the right gastro-epiploic branch of the hepatic artery. The splenic vein joins the superior mesenteric to form the portal vein.

When the spleen is of normal size and retains its proper relations with the stomach, the vessels can easily be secured by transfixing the pedicle with a double ligature as in ovariotomy, but with a spleen measuring eighteen inches or more in length and weighing four or five pounds, the pedicle cannot be safely secured in this way. A mobile spleen lodged in the pelvis is conveniently exposed by a median sub-umbilical incision, and, if it be free from adhesions, such a spleen is 


\section{THE BRITISH JOURNAL OF SURGERY}

easily withdrawn from the abdomen; this allows the pedicle to be transfixed with a double ligature of silk, and tied. For security, an encircling ligature may be placed around the whole pedicle. In its simplest form the pedicle consists of the branches of the splenic artery and vein, and the peritoneum forming the gastro-splenic omentum. Occasionally, the tail of the pancreas has been included in the ligature, but this is of no consequence, except that additional care must be exercised in tightening the ligatures. As soon as the spleen is detached, the tissues of the pedicle, being elastic, quickly recede from view, and slip away under the left costal arch.

Occasionally, a pelvic spleen will adhere to the uterus, intestines, or omentum ; such conditions are dealt with in the same manner as adherent ovarian tumours.

When the spleen is big, and reaching perhaps from the diaphragm to the pelvis, it is best exposed by an incision in the left linea semilunaris. It is quite easy to withdraw the lower half of a big spleen through the abdominal incision, but the upper pole is held by the phrenico-colic ligament and embarrasses the surgeon. It is of the utmost importance to set free the upper pole in order to obtain the control of the spleen. For this purpose the peritoneal ligament, which retains the upper pole of the spleen to the diaphragm, is divided cautiously with scissors; this allows the spleen to be withdrawn from the abdomen. Then the various branches of the artery are secured with hæmostatic forceps and divided close to the spleen, in order to avoid injury to the stomach. After the spleen is detached, each branch of the artery is ligatured in turn. With a big spleen, sometimes ten or twelve ligatures will be required. On two occasions when removing a very large spleen, the big splenic artery has pulsated so forcibly that I have scratched a hole with forceps through the overlying lesser omentum and ligatured the trunk in continuity; but this is an unnecessary refinement. Too much care cannot be expended in securing the vessels; one of the greatest dangers of splenectomy lies in the slipping of ill-applied ligatures after the patient has been returned to bed.

The abdominal wound is sutured according to the predilection of the operator. The success of splenectomy in appropriate cases depends, as in the surgical treatment of lesions of abdominal viscera in general, on rigid ascpsis and the careful application of ligatures.

Accessory Spleens.-One or more small spleens in the neighbourhood of the hilum are by no means uncommon, and it is often recommended, in performing splenectomy, that the surgeon should look out for satellite spleens and leave them in situ whenever such a course is possible. Experience teaches that this is unnecessary.

The chief abnormality of the spleen relates to transposition of the viscera. The spleen is loyal to the stomach; when this viscus is transposed, the spleen lies in the right hypochondrium. Sometimes the spleen is represented by a number of splenculi, and in a case of transposition of viscera described by Abernethy (I793) the spleen consisted of seven separate portions, and a branch of the splenic artery was distributed to each.

Albrecht has described in detail the most extraordinary example of multiple spleens on record. A man, aged 25, died of nephritis, and post mortem his peritoneum was found sprinkled with a multitude of minute spleens. A spleen the size of a walnut was present in the usual position, and supplied by a normal 


\section{SURGERY OF THE SPLEEN}

splenic artery and vein. An immense number of small supernumerary spleens were sprinkled throughout the abdomen. They grew from the ligaments of the liver, the mesentery, the mesocolon, and the peritoneum of the recto-vesical fossa. Each little spleen was red, and consisted of pulp with microscopic features of the spleen, had its own capsule, and was covered with peritoneum.

Another rare anomaly of the spleen is mentioned by Rolleston: The spleen gave off a long process which was bound down to the posterior abdominal wall by the peritoneum and ran down to the left side of the scrotum. In thickness it was. equal to the little finger. Microscopically it was composed of splenic tissue. This observation was made in the post-mortem room. Hutchinson met with a long-tailed spleen of this sort in the course of an operation for hernia on a boy. He found a band connected with the testicle, followed it into the abdomen, and traced it upwards till it joined the spleen.

A curious set of symptoms has been noticed to follow splenectomy. As a rule, patients who have had the spleen removed suffer no more inconvenience than after ovariotomy, but in some instances the patient, a few days after the operation, has become very ill; the temperature rising to $101^{\circ}$ or $103^{\circ}$ at night, accompanied with loss of flesh, and pain in the long bones, especially the bones of the lower limbs. Associated with these changes there has been a diminution in the number of the red, and an increase in the number of the white, corpuscles. In a. few cases there has been a temporary enlargement of the lymph-glands. I have seen these signs supervene in one patient after splenectomy. In all cases in which these unpleasant sequelæ have been reported, they gradually subsided. Probably such symptoms are due to infective changes about the stump.

Vulpius reported an interesting series of experimental splenectomies on animals (I894), and mentions that in young animals, where red marrow is present in quantity, there were no symptoms following the removal of the spleen; but in old animals there was increase of temperature and loss of flesh. This is true of man: adolescents bear splenectomy better than adults.

In regard to the enlargement of lymphatic glands after splenectomy, it has been suggested that bone-marrow takes on the function of the spleen pulp, and the lymph-glands act for the Malpighian bodies. This is mere surmise.

Vulpius records an interesting observation in one of his splenectomized dogs: The abdominal lymph-glands enlarged, and a multitude of miliary bodies were found on the peritoneum and omentum; in structure they were like the Malpighian bodies of the spleen, but in the light of Albrecht's interesting observation, previously mentioned, it is doubtful whether this peculiarity can be regarded as a sequel of the removal of the spleen.

The spleen may be regarded as an enormous lymph-gland, and its ablation exercises no graver influence on the body than the excision of a crowd of enlarged lymph-nodes from the neck, axilla, or groin.

The Statistics of Splenectomy.-Many industrious surgical writers have collected and tabulated the records relating to removal of the spleen. Conspicuous among them are Adelmann, Vulpius (I894), Berger (I902), BesselHagen (I900), Johnston (I908), and Moynihan and Upcott (Igr3). These analytical efforts have established certain important facts :-

1. The removal of the spleen in patients with leukæmia is the most fatat 
operation in surgery. Probably no leukæmic patient has recovered from this operation : death is due in most cases to uncontrollable bleeding or to shock.

2. Splenectomy for wandering spleen is accompanied by the same risks that beset an uncomplicated ovariotomy.

3. The removal of a malarial spleen is attended with a great risk: probably 30 per cent when the spleen lies in its normal position ; but if free and mobile, the risks approximate to those attending a straightforward ovariotomy.

4. The risks attending the removal of enlarged spleens in the category of splenomegaly associated with anæmia are great; but the death-rate varies with the skill and experience of the operator.

When, after careful choice of cases, surgeons made splenectomy a success, pessimists admitted the surgical brilliancy of the results, but urged the importance of time to prove the ultimate success of such enterprises. Time has admirably vindicated the activity of the surgeon in regard to the spleen. It is encouraging to realize that, when patients recover from splenectomy, there is nothing in their condition to suggest that they are spleenless.

\section{APPENDIX.}

Short notes of ten cases in which the anthor removed the spleen and was able to obtain the subsequent history of the patient.

Case r.-Wandering Spleen, Axial Rotation.

Woman, aged 22. Mother of one child. Splenectomy, 1892. Blood-count normal at the time of the operation; it was examined at intervals during the next three years and remained normal. Patient in good health 1898 . (Clinical Society's Transactions, xxvi, 46, and xxxiv, 32.)

Case 2.-Wandering Spleen.

Woman, aged 33. Mother of four children. Splenectomy, I895. A piece of the tail of the pancreas involved in the pedicle was removed also. Patient in excellent health rgoo, and instead of being a "thin woman" is quite plump. A similar report was made two years later. (Lancet, 1895, ii, 974 ; Clinucal Socuety's Transactrons, xxxiv, 32.)

Case 3.-Wandering Spleen.

Woman, aged 34. Mother of seven children. Splenectomy, rgoo. Patient two months advanced in pregnancy at the time of the operation. Seven months later was delivered of a living healthy baby, and reported herself in excellent health, January, Igor. (Clinucal Socuty's Transactions, xxxiv, 33.)

Case 4-W -Wandering Spleen.

Woman, aged 33. Large spleen lodged in the pelvis and resembled a subserous fibroid, but correctly diagnosed as a pelvic spleen. Splenectomy, I9o6. During convalescence, the patient had fever, restlessness, rapid pulse, and pain in the legs, especially the thighs. On the twelfth day a large quantity of pus was discharged from the anus. The symptoms disappeared, and she made a good recovery. Reports of her condition were obtained at two-yearly intervals. They were always to the effect that she was in excellent health. The last report was received in April, rgr3.

Case 5-Tuberculous Spleen.

Woman, aged $2 \mathbf{x}$. Mother of one child. Splenectomy, I897, for a wandering spleen; it contained a multitude of tuberculous deposits. She had a quiescent cavity in the lung. In good health rgoo. Nolater report. (Practitioner, 1898, 828; Clinucal Society's Transactions, $\mathrm{xx \times v}, 33$. 


\section{SURGERY OF THE SPLEEN}

Case 6.-Spleen Lacerated during an Operation.

Woman, aged 35. Spleen broken in halves during an operation for relief of an abscess in the ileo-costal space, 1897. The abscess was a sequel to an attack of pelvic cellulitis following childbirth. Patient was in good health in 1899 , and a later report in 1910 was to the same effect. (Clinical Journal, 1897, x, 369.)

Case 7.-Gunshot Wound of Spleen.

A youth, aged $\mathrm{r} 7$, shot himself in chest with a revolver. The bullet traversed the left lung, stomach (both walls), and the spleen. Splenectomy, January, I9II. $\mathrm{He}$ was in good health and resumed work as a footman, November, 19II. Seen again in the winter of rgr2: in good health.

Cas: 8.-Splenomegaly.

Girl, aged 5. Large spleen associated with anamia. Splenectomy, I895. The anæmia quickly disappeared, and she became strong and well. In Igoo she was reported to be " very well, looks healthy, is of average height, but rather thin." In I9I 3 reported to be a healthy, attractive, and handsome woman. Private report. (Lancet, I895, ii, 974. Clinucal Society's Transactions, xxxiv, 32.)

Case 9.-Splenomegaly.

Girl, aged 17 years. Very large spleen associated with anæmia and jaundice. Splenectomy, I895. She reported herself in robust health 1900. (Lancet, 1895, ii, 974. Clinucal Society's Transactions, xxxiv, 32.)

Case ro.-Splenomegaly.

Female, aged 22. Jaundiced from birth-acholuric jaundice, anæmia, and splenomegaly. Splenectomy, I9r2. The spleen weighed three pounds. Patient rapidly improved and the jaundice disappeared. (Dr. W. Essex Wynter.)

\section{REFERENCES}

ABERnethy, Phil. Trans., I793, Ixxxiji. 59.

Ademmann, G., Die Wandlungen der Splenectomie seit dreissig Jahren. Arch.f. klin. Chir., I887, xxxvi, 442 .

ALBRECHT, H., Ein Fall von sehr Zahlreichen über das ganze Peritoneum versprengten

Nebenmilzen. Beit. z. Path. Anat., I896, xx, 5 I3.

Allbutit and Rolleston, System of Medicine, and Ed., r903. iv, pt. i, 444.

Berger. Die Verletzungen der Milz und ihre Chirurgische Behandlung. Arch. $f$. klin. Chir., I902, Ixviii, 768.

Bland-Sution, J., Three Cases of Splenectomy; Lancet, 1905, ii, 974 ; also Trans.

Clin. Soc., London, I893, xxvi, 46, and I901, xoxiv, 32, and Practitioney, 1898, lx, 288.

BRown, H., Splenectomy for Prolapse of the Spleen through a Perforating Wound of the abdomen. Brit. Med. Jour., I897, i. I33.

Curtis, H., and Lawrence, T. W. P., Case of Portal Thrombosis, etc.; Proc. Roy. Soc.

Med. London, rgog; Path. Sec., ii, I59.

Edens, Uber Milzvenenthrombose und Bantische Krankheit Mitt. aus d. Grenzg. d. Med.

u. Chir., Bd. xviii, 1907, 59 .

Ewald, C. A., Milzen Venenthrombose mit tödlicher Magenblutung. Deut. med. Woch., I9I3, xxxix, 398 .

Fischer, V., Ein Beitrag zur Kenntniss des isolierten Milztuberkulose. Wien. med. Woch. I909, No. 43. 2506.

Fowler, R. H., Cysts of the Spleen. Ann. Surg., 19r $3,658$.

HAGEN, F. B., Ein Beitrag zur Milzchirurgie. Verhandl. der deutschen Gesellschaft $f$, Chir., Berlin, rgoo, xxix, 7 I4.

Hutchinson, J., A Case of Lieno-testicular Band or Ligament. Proc. Roy. Soc. Med., I9I 3. Surgical Section, vi, $24 \mathbf{I}$.

Johnsron, G. B., Splenectomy. Report of Six Cases, with a Statistical Summary of all the reported cases up to the year 1908. Ann. Surgery, 1908, xlviii, 50.

Kind, F., Case of Banti's Disease cured by Splenectomy. Proc. Roy. Soc., I9r3, Surgical Section, vi, 225.

Ledderhose, G., Die chirurgischen Krankheiten der Milz; Deut. Chrr., Ljef $45 \mathrm{~b}$. Stuttgart, 1890. 


\section{THE BRITISH JOURNAL OF SURGERY}

Macdonald, I., And Mackay, W. A., A Case of Acute Torsion of a Wandering Spleen. Lancet, Igog, ii, 917.

McGRAw, T. G., A Case of Excision of a Dislocated Spleen and Subsequent Expectoration of the Ligature of the Pedicle. Med. Rec., New York, I888, xxxiii, 7 no.

Marriotr, C., Acute Tuberculosis of the Spleen: Splenectomy. Recovery. Trans. Path. Soc., Lond., I896, xlvii, 96.

Mayo, W. J., The Surgery of the Spleen. Suvg., Gyn. and Obsi., r9r3, xvi, 233.

Moynihain, Sir B., And Ufcott, H., Surgery of the Spleen. In. Keen's Surgery, I9I3, vii., 6rg.

NoGUchr, Y., Ueber die Exstirpation der normalen Milz beim Menschen. Berl. klin. Woch., I9I 2, Sept. 23, 1839 .

OSLER, W., Erythræma. (Polycythæmia with Cyanosis, Maladie de Vaquez). Lancet, I908, $\mathrm{i}, \mathrm{I} 43$.

PICK, L., Uber totale hämangiomatöse obliteration des Pfortaderstammes und über hepatopetale Kollateralbahnen. Virchow's Archtv., r909, Bd. 197, S. 490.

PLINY, Historia Naturalis. Lib. xl, 80.

Rolleston, System of Medicine, rgo8, iv, Pt. i, 444.

VARINEK, L. N., Brit. Gyn. Jour., I894, x., 4 Io.

Vircent, E., Réflexions sur le Prognostic et le Traitement des Ruptures de la Ratc. Rsvue de Chrv., I893, xiii, 449. xi., 633

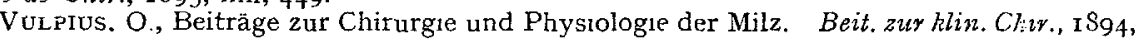

Watson-Wemyss, H. L., A Case of Vaquez's Disease (with references). Brit Med. Jour., Igr $3, \mathrm{i}$, , 02.

Weber, F. P., Four Cases of Congenital Acholuric (so-called hæmolytic) Jaundice in one Family. Trans. Med. Soc. Lond., 1910, xxxiii, 346.

Wells, Sir T. S., Remarks on Splenectomy. Med. Chry. Trans., Lond., I888, 1xxi, 255.

Wilson, F. E., Notes on Threc Cases of Splenic Abscess occurring in so-called Malarial Cachexia. Lancet, igr 3,1, I 162.

Winckler, V., Ein Fall von Milzextirpation wegen Aneurysma der Arteria Lienalis. Centralbl. $t$. Chtr., I905, xxxii, 257.

Wynter, W. E., Case of Acholuric Jaundice. Proc. Roy. Soc. Meä., I913, Clinical Section, 33 and 80 . 